\title{
Erratum to: Comparison of the Simple Patient-Centric Atopic Dermatitis Scoring System PEST with SCORAD in Young Children Using a Ceramide Dominant Therapeutic Moisturizer
}

\author{
Mark Jean-Ann Koh · Yoke Chin Giam · Hui Min Liew · Alice Yee-Wah Foong • \\ Jin Ho Chong · Sharon Mun Yee Wong · Mark Boon Yang Tang • Madeline Sheun Ling Ho • \\ Lucinda Siyun Tan · James M. Mason · Michael J. Cork (D)
}

Published online: July 4, 2017

(C) The Author(s) 2017. This article is an open access publication

Erratum to: Dermatol Ther (Heidelb)

DOI 10.1007/s13555-017-0186-1

Unfortunately, the given name and family name of the co-author Dr. Jin Ho Chong was incorrectly published in the original publication. The correct given name and family name should read as 'Jin Ho' and 'Chong', respectively.

The original article has been updated.

The online version of the original article can be found under doi:10.1007/s13555-017-0186-1.

M. J.-A. Koh · H. M. Liew · A. Y.-W. Foong ·

J. H. Chong · S. M. Y. Wong

KK Women's and Children's Hospital, Bukit Timah, Singapore, Singapore

Y. C. Giam - M. B. Y. Tang · M. S. L. Ho · L. S. Tan National Skin Centre, Mandalay Road, Singapore,

Singapore

J. M. Mason

Warwick Medical School, University of Warwick, Coventry, UK

\section{J. Cork ( $\square)$}

Dermatology Research Group, Department of Infection, Immunity and Cardiovascular Disease, Faculty of Medicine, Dentistry and Health, University of Sheffield Medical School, Beech Hill Road, Sheffield, UK

e-mail: m.j.cork@sheffield.ac.uk
Open Access. This article is distributed under the terms of the Creative Commons Attribution-NonCommercial 4.0 International License (http://creativecommons.org/licenses/ by-nc/4.0/), which permits any noncommercial use, distribution, and reproduction in any medium, provided you give appropriate credit to the original author(s) and the source, provide a link to the Creative Commons license, and indicate if changes were made. 